\title{
A mixagem como leitura/escuta de narrativas do território
}

\author{
João Pedro Goulart da Silva (i) \\ Roberto Henrique Amorim de Medeiros*
}

Universidade Federal do Rio Grande do Sul, Porto Alegre, RS, Brasil

\begin{abstract}
Resumo: 0 artigo é fruto de um recorte de investigação autoral dentro de uma pesquisa que tem por objetivo reconhecer territórios a partir de suas narrativas. O método da clínica de território, baseado na deriva, na escuta e na escrita, com vistas ao mapeamento, foi experimentado pelo autor principal sob orientação do coautor. Frases e expressões escritas em muros e paredes, chamadas neste trabalho de "grapixos", foram escutadas como narrativas do território a partir da construção de um procedimento chamado de "mixagem de textos". O objetivo deste trabalho é apresentar a proposta da mixagem como forma de ler/escutar narrativas de espaços territoriais e analisar seus problemas, suas potencialidades e seus resultados. Como resultado principal, comprovou-se que a mixagem dos textos dos grapixos com as "escrevivências" do pesquisador é um método pertinente para revelar outras camadas discursivas do território não em evidência ou silenciadas.
\end{abstract}

Palavras-chave: mixagem. leitura. escuta. narrativa. território.

\section{Introdução}

O trabalho com narrativas é comum a inúmeros campos do saber e costuma figurar com frequência em trabalhos técnicos, científicos ou culturais. Na psicanálise, na etnografia, passando pela literatura e até mesmo na medicina, $o$ ato de narrar pode ocupar lugar fundamental, mas certamente é compreendido e utilizado de diferentes modos em cada campo. O trabalho a partir do espaço, do lugar, do território e suas territorialidades também interessa a uma vasta gama de campos da ciência, que vão das humanas e sociais às exatas ou aplicadas, como as engenharias e a arquitetura e urbanismo. Porém um trabalho sustentado na articulação entre território e narrativa parece compreender um campo mais restrito e, necessariamente, multidisciplinar.

Entretanto, seria possível estruturar uma forma de proceder que permita reconhecer um território atenuando, em alguma medida, as capturas conceituais disciplinares a priori, baseado em suas narrativas singulares e cujo produto seja um tipo de mapeamento menos descritivo ou representativo a partir de convenções ou analogias e, ao invés disso, mais analítico e expressivo a respeito de seus fenômenos?

A busca por uma forma de reconhecimento de territórios - neste estudo, compreendemos território não apenas como o espaço geopolítico demarcado num espaço material, mas a relação social, os processos históricos, as territorialidades de seus indivíduos e a cultura do coletivo, seus modos de vida, necessidades, especificidades, problemas ou potencialidades etc. - com vistas ao mapeamento desses elementos e possíveis estabelecimentos de ações de promoção

* Endereço para correspondência: robertoamorim80@hotmail.com em saúde coletiva, organização popular, entre outros, inspirou o procedimento da mixagem como leitura/escuta de narrativas do território: uma das primeiras produções da articulação que iniciou, em 2017, entre um projeto de extensão intitulado Clínicas de Território e outro, de pesquisa, nomeado A contribuição do método investigativo psicanalítico para a construção de territórios baseados em narrativas.

Como será melhor descrito na próxima seção do artigo, o projeto de extensão proporcionou experimentações do espaço urbano por meio de caminhadas sem um objetivo específico a ser atingido a priori. Esse procedimento mostrou seu poder de criar situações de interpelação do território aos participantes da experiência, o que acabava por constituir espaços de escuta de narrativas sem um enquadre premeditado. $\mathrm{O}$ projeto de pesquisa, associado posteriormente, veio para tentar formalizar o estudo da constituição desses espaços de escuta de narrativas e experimentar modos de dar tratamento expressivo - não representativo ou descritivo - às narrativas deduzidas das experiências resultantes das caminhadas e das interpelações do território, para a construção de mapeamentos baseados em narrativas. $\mathrm{O}$ resultado da conjugação de ambos foi o estabelecimento da estrutura procedimental - derivarescutar-escrever-mapear - produzida sob a denominação de Clínicas de território, com a qual cada um passa a coloca algo de si, de seu estilo articulado a demandas ou especificidades do território em que se dá seu trabalho de investigação/experimentação, para produzir um mapeamento, que pode se apresentar de diferentes formas expressivas. No caso da pesquisa em questão, a forma encontrada no processo singular de investigação foi a mixagem de textos.

O aprofundamento acerca da produção do conceito de Clínicas de Território e sua estrutura procedimental 
é objeto de outros dois artigos ainda não publicados até o momento. Este artigo tem por objetivo apresentar, discutir e refletir acerca dos resultados de uma experiência prática com a estrutura procedimental desenvolvida como pesquisa autônoma a partir dos projetos de extensão e pesquisa da qual a mixagem de textos acabou por se constituir como materialização de um método de leitura/escuta de narrativas do território.

Assume-se que o resultado obtido, a ser apresentado neste trabalho, observou os princípios gerais dos projetos que o originaram ao diferenciar-se dos métodos tradicionais e disciplinares de coleta de dados - por questionários, estatísticas, georreferenciamentos etc. - e ter encontrado uma forma de incluir o sujeito e suas territorialidades no mapeamento expressivo do território, gerando um saber acerca de aspectos determinantes dos modos de viver e de padecer nos espaços urbanos.

Como anunciado, passaremos a descrever sucintamente como se articularam os projetos de extensão e de pesquisa a partir dos quais foram produzidos os resultados contidos neste trabalho, para em seguida especificar: os pressupostos epistemológicos e teóricos que permitiram construir o método da mixagem como mapeamento do território baseado em narrativas, examinar seus problemas e, por fim, apresentar e discutir seus primeiros resultados.

\section{Uma Clínica de Território: origens na extensão e na pesquisa}

\section{O projeto de extensão}

A extensão universitária Clínicas de Território é um projeto desenvolvido no departamento de Saúde Coletiva da Universidade Federal do Rio Grande do Sul, que convida alunes de diversos cursos da saúde, das ciências sociais e humanas, da arquitetura e urbanismo, entre outros interessados, a experimentar o encontro com narrativas e a experiência com a produção coletiva de mapeamentos acerca da experiência no território. No início do projeto, em 2016, não havia formalização teórica ou metodológica, apenas um princípio ético de colocar-se à escuta no território evitando uma posição prévia de saber ou uso instrumental de protocolo de levantamento de dados sustentados por alguma intencionalidade privilegiada no processo. O objetivo se resumia em experimentar o espaço urbano por meio de caminhadas, se possível escutar narrativas locais e tentar produzir uma forma expressiva individual ou coletiva que pudesse transmitir algo da experiência de imersão no espaço urbano eleito como cenário daquela prática.

Com o tempo, a extensão Clínicas de Território vai ganhando um procedimento construído coletivamente por meio das experiências de cada grupo de extensionistas, ano após ano. A pesquisa associada ao projeto acabou por formalizar um procedimento baseado em quatro elementos: derivar pelo território - caminhar a pé sem um roteiro estabelecido, deixando-se levar pelas circunstâncias (Debord, 2003) -, escutar narrativas a partir do encontro fortuito promovido pela deriva, expressar a experiência de escuta por meio da escrita e investigar modos de mapeamento expressivo, buscando escapar da descrição ou representação. Esse método segue sendo experimentado como procedimento de pesquisa e extensão, cujo propósito é encontrar formas de produzir conhecimento acerca dos modos de vida nas cidades e compreender as construções subjetivas locais para lidar com os problemas, procurando atenuar chaves de leitura predeterminadas. Trata-se de uma investigação e experimentação de possibilidades críticas aos regimes de saber e poder inevitáveis, mas passíveis de atenuação, para a produção do conhecimento e estabelecimento de ações no território vivo, onde relações sociais e espaço se encontram e se reproduzem.

\section{O projeto de pesquisa}

O método investigativo psicanalítico pouco se diferencia da sua clínica (Dunker, 2017). A clínica psicanalítica é um dispositivo de fala e escuta baseado numa relação de endereçamento, suposição de saber e confiança entre quem narra e quem escuta, formalizada por Freud pelo conceito de transferência (Freud, 1912/2006). Para o objetivo de produzir o mapeamento a partir de narrativas, era preciso resolver como nos aproximaríamos de um território, das suas histórias, dos seus modos de vida, escapando de uma roteirização e, ainda, problematizar como se constituiria a condição transferencial para o endereçamento narrativo sem que a demanda fosse invertida, ou seja, sem que ela partisse dos pesquisadores. Pela experiência da extensão, encontramos a deriva como prática psicogeográfica (Debord, 2003) que permite provocar o território a nos endereçar um estranhamento e uma interpelação e, assim, disparar a possibilidade de um encontro menos premeditado para a escuta de uma narrativa livre da captura de consignas prévias.

A pesquisa associada ao projeto de extensão auxiliou a formalização teórica e crítica acerca das experiências de campo produzidas concomitantemente pelos participantes da extensão. Como resultado, estabeleceu a estrutura mínima que constitui uma proposta conceitual baseada no ato de derivar, escutar, escrever, que pode orientar práticas distintas de reconhecer territórios, mapeá-los a partir de narrativas, com vistas a projetos singulares de ação coletiva conforme os objetivos de quem o procede.

É preciso ressaltar que a orientação pela estrutura do que temos tentado formalizar sob o nome de Clínicas de Território implica que cada qual seja um pesquisador singular. Considerando isso, a próxima seção será escrita em primeira pessoa do singular, acerca dos fundamentos epistemológicos e conceituais que dão rigor à construção do procedimento da mixagem de textos, pois ele adveio da singularidade do trabalho do autor principal. Em seguida, encontra-se uma seção metodológica que explicita o procedimento que é o objeto deste artigo e que 
reflete sobre seus limites e potencialidades. Na parte final, em que será apresentada a análise e discussão dos resultados que dão validade ao procedimento da mixagem, voltaremos a utilizar a voz no plural por se tratar de um esforço coletivo dos autores no contexto do grupo de pesquisa e extensão.

\section{Fundamentos, conceitos e epistemologia da mixagem como leitura/escuta de narrativas do território}

\section{O encontro com o problema}

No projeto de extensão, decidimos que as semelhanças com a realidade urbana do país - o terreno acidentado, a proximidade de residências de classes diferentes, a ausência do Estado, a presença do tráfico etc. - fariam de um bairro periférico de Porto Alegre (RS) um cenário representativo da realidade comum às grandes cidades. Mas ainda havia uma questão: como nos aproximaríamos do território, de suas histórias, seus modos de vida, escapando da roteirização que denunciava uma intencionalidade a priori? Por meio dos seminários do projeto, encontrou-se a teoria da deriva (Debord, 2003) como método de encontro inesperado com a cidade e que propõe àquele que deriva - que caminha a pé (Careri, 2003) - seguir seus sentidos ao traçar seu roteiro no ato de caminhar; derivar está na ordem do afeto, não do lógico e da intenção. Depois, seguindo o conceito de deriva, a meta foi tentar criar situações para o encontro com narrativas locais - essa foi a minha maior dificuldade. Outros colegas já começavam a trazer o resultado de seus encontros com narradores em um bar, numa escola ou mesmo na rua. Minhas derivas levaram a mercearias, pequenas lojas, salão de beleza, uma ferragem, bares, praças e, em todos esses lugares, a resposta era sempre a mesma: "estou ocupado, não posso falar", ainda que esses comércios estivessem vazios.

Frustrado, desistia e voltava para casa. No caminho, um dia deparei com um muro branco e uma frase: "te expus um livro de opções, 'mais' suas decisões optaram pelo silêncio". Desde então tomei os grapixos como narrativa do território e paro para ler/escutar o que eles têm a me dizer. A título de esclarecimento, não tomo a palavra "grapixo" para destacar um estilo artístico, mas como forma de não fazer uma diferenciação entre grafite e pichação.

Fiquei um bom tempo apenas lendo-escutando as paredes até me sentir confortável com a ideia de escrever algo - todos os demais integrantes do projeto já haviam experimentado alguma forma expressiva de transmitir a experiência de suas primeiras escutas. Tentei fazer no mesmo formato que alguns deles, mas o resultado não se pareceu nem com a escrita deles, nem com a minha. Foi um desafio encontrar uma escrita que transmitisse a experiência com a escuta dos muros do território.

\section{Histórias negras: um fundamento epistemológico}

A mixagem é uma mistura de dois ou mais elementos de mesmo caráter. O DJ mistura sons. Para justificar esse mesmo rigor no método de mixagem de textos advindos do grapixo e da poesia rap, mostrarei o nexo narrativo que os aproxima e que, assim, me permite mixá-los.

Graffiti é o plural de graffito, que na língua italiana significa rabisco. Grafites são conhecidos desde o Império Romano pela utilização de carvão para escrever palavras de protestos nas paredes, embora o desenho/escrita em paredes se reconheça na arte rupestre, desde a Pré-História. Os desenhos em grafite deram início a um grande movimento de arte urbana nos anos 1960, quando jovens de bairros periféricos de Nova Iorque começaram a espalhar suas marcas na cidade com tinta spray. $\mathrm{O}$ grapixo se torna reconhecido no meio artístico devido ao trabalho de Jean-Michel Basquiat (Warburg Banco Comparativo de Imagens, 2021), que passou a desenhar e escrever nas paredes de seu bairro, o Bronx. Basquiat criou algumas das obras de arte mais expressivas do século XX. Em Flexible e em Gold Griot, obras de 1984, vemos figuras humanas negras. Um griot é aquele que tem o poder da narrativa e da transmissão da cultura de matriz africana. Michel Pollak (1992) afirma que as memórias são constitutivas da identidade, tanto individuais quanto coletivas. Ele também diz que há disputas em torno dessas memórias, a fim de estabelecer qual história deve ser contada e qual deve ser lançada à margem. Os griôs, conhecidos como guardiões da memória, têm como função levar a cultura de um povo para as próximas gerações. Exu, por sua vez, é o senhor das mensagens, das comunicações. Por isso, afirmo que flexible também pode ser lido como Exu, nome também de uma obra de 1988, ano da morte de Basquiat.

Exu é o orixá sempre presente, pois o culto dos demais depende de seu papel de mensageiro (Prandi, 2001). Sem ele, orixás e humanos não podem se comunicar. Numa das histórias sobre Exu, diz-se que há meses os orixás passavam fome, pois os homens haviam deixado de lhes fazer oferendas. A fim de resolver essa situação, Exu foi se aconselhar com Orungã, que disse ao jovem orixá para encontrar 16 cocos de palmeira e dar um sentido diferente para cada um deles. Exu andou pelo mundo e perguntou o que significavam aqueles cocos. Ele foi a 16 lugares e, em cada lugar, recolheria 16 odus, 16 histórias, 16 oráculos - cada história contendo sua sabedoria. No final da jornada, Exu retornou e mostrou aos demais orixás os odus que havia aprendido. Então os orixás ensinaram o novo saber aos homens. A partir daquele momento, os homens reaprenderam a fazer sacrifício aos orixás para afastar os males que o amanhã traria, pois passaram a saber o que aconteceria no futuro jogando os 16 cocos de dendê. Pereira (2015) reafirma Exu como grande contador de histórias, o responsável pela comunicação entre os humanos e os outros deuses do panteão africano. Exu poderia ser o primeiro griot?

Um griot é um contador de histórias da África Ocidental. É o responsável pela transmissão oral da cultura de um povo e seus valores morais construídos com o tempo. Há várias modalidades de griots: instrumentistas, cantores, animadores, poetas, artistas ou mesmo os anciãos detentores de histórias que passam geracionalmente pela oralidade. Mesmo os 
babalorixás e as ialorixás, conhecidos também como pais e mães de santo, ou demais instituições de contadores de histórias, têm por objetivo manter viva a tradição da oralidade africana, como os ditados populares.

Dentre as formas recentes de cultura oral, escolhi o rap para me expressar. Salomão (citado por Salles, 2007) diz que o rapper põe em relevo a fala dos que não falam seja por não conseguir falar, seja por não saber como falar ou por não serem ouvidos. Tendo sua voz desconsiderada, invisibilizada, se esforça em se fazer entender pelos seus da melhor maneira possível. O maior ato político do negro em uma sociedade racista e genocida é manter-se vivo. Retirar dele formas pelas quais exercem sua voz política é tirar o que resta de humanidade dos sujeitos negros desde o período colonial.

Nesse papel, o rap se aproxima do grapixo. Um dos estilos que o rap abriga é o storytelling, cujos maiores representantes são Slick Rick e Notorious BIG, ambos estadunidenses, e Racionais MC's, no Brasil. Recentemente, outros nomes do rap seguem contando histórias que dizem de um lugar coletivo, como Thiago Elniño, em seu álbum A rotina do pombo (Thiago Elniño, 2017). Nele, conta a história de um trabalhador por meio da qual faz críticas ao sistema racista que ensina ao negro se odiar, cujo colégio tem por objetivo criar mão de obra ("Pedagoginga") para que, mais tarde, no mercado de trabalho, tenha que se vender por pouco ("Qual é o seu preço?" e "Trabalhar sem comer"). Mas Elniño também fala das potências: diversão, festas, união, religião, ou seja, fala de vida em meio a mortes. Djonga, outro nome recente do rap nacional, afirma: "quando falo do Djonga, também falo de você" (Rap da Hora, 2020).

Até aqui, em um percurso conceitual, reuniram-se passagens que aproximaram o grapixo do rap. Evidenciou-se poder atribuir a ambos tanto o status de expressão de uma coletividade quanto o de escrevivência. Por essas características comuns, podem ser mixadas, segundo esta proposta de método a partir da noção de Clínicas de Território. O que está escrito nos muros também precisa ser lido como uma narrativa do território. O método da mixagem é uma condição de sua possibilidade.

\section{Método}

\section{A construção metodológica}

Em Conceição Evaristo (2017), encontramos a afirmação contemporânea do potencial da narrativa na cultura de matriz africana, na qual a transmissão oral ou a narrativa escrita tem papel fundamental na construção do laço social e da transmissão da experiência coletiva do povo negro. Conceição Evaristo, em Becos da memória, cunha o termo escrevivência, que, embora parta de uma narrativa escrita e pessoal, reconstrói experiências coletivizadas.

O contato com o pensamento de Evaristo me permite encontrar o rumo de minha leitura/escuta e escrita após a deriva inicial pelo território. A fim de conseguir expressar o que escutava dos grapixos, encontrei a forma da escrevivência. Há alguns motivos para isso. Primeiro, quero que meu trabalho seja essencialmente negro. Desde a narrativa até minha escrita. Desejo denegrir (tornar negro) este artigo, a academia e (meus) saberes. Em segundo lugar, porque a escrevivência diz, ao mesmo tempo, de uma escrita tanto de si como de um coletivo. E, em terceiro, porque desejo escrever em outro cânone acadêmico, não eurocêntrico, mas decolonial. Eu vim de África, e lá a transmissão é baseada na oralidade. Escreviver permitiria contar histórias ao modo de uma fala. E meu modo expressivo tem a forma de poemas.

A intimidade com o movimento hip hop me fez perceber que, ao definir a poesia do rap como forma de dar expressividade ao grafite dos muros, eu estaria operando com dois de seus quatro fundamentos: MC (que se vale do rap); o DJ (disc jockey), o grafite e o break dance.

Originalmente, o DJ era o animador de um programa musical em rádio. Em meados dos anos 1970, tornou-se um criador completo. Nas festas que aconteciam nos guetos, faziam mixagem ao vivo de gravações em vinil, misturando as batidas e produzindo outras sonoridades. Algumas das técnicas são o back spin (ato de manipular o vinil com força suficiente para que ele volte para um trecho específico da música); back to back (repetição de um trecho da música, feita por um ou dois DJs a partir de duas cópias do mesmo vinil); scratch (movimento anti-horário da agulha do toca-discos sobre o vinil que produz sons de fricção e de quebras, respeitando a cadência rítmica da música). Grafites, por sua vez, são pinturas ou escritas feitas com spray sobre variadas superfícies. Na década de 1970, a prática do grafite é apropriada pelos latinos e, sobretudo, pelos negros dos guetos de Nova Iorque, que fizeram dela um ótimo veículo de sua indignação. $\mathrm{O}$ MC é aquele que fala enquanto a batida mixada do DJ é tocada, também reconhecido como rapper, que canta ou declama uma poesia baseada no ritmo (a sigla "RAP" abrevia a frase ritmo e poesia, no inglês). Como afirma Salles (2007), em Poesia revoltada, o hip hop se torna forma de organização sociocultural e de expressão de uma produção frequentemente marginalizada.

Como escuta e escrita, com vistas ao mapeamento expressivo de aspectos territoriais baseados em narrativas, passei a conceber a estrutura de um método inspirado em três dos elementos da cultura hip hop. No grafite, há sempre uma narrativa. No DJ, o ato de mixar dois elementos e produzir um terceiro. Na produção poética do MC (rapper),uma possibilidade de escrevivência.

Meu procedimento consiste, portanto, em derivar para encontrar muros-narradores. Em seguida, escutar as narrativas do território a partir da mixagem da escrevivência dos grapixos com o texto produzido em forma de poesia rap que constitui minha escrevivência. $\mathrm{O}$ que resulta como terceiro texto a partir da mixagem entre a escrevivência do grapixo e minha escrevivência produzirá uma forma potencial e singular de mapeamento 
expressivo do território. Em resumo, o processo de mixagem engloba três elementos: o que chamaremos de texto 1 é a escrevivência contida no grapixo; o texto 2 é a escrevivência em forma de poesia produzida pelo pesquisador; e o texto 3 , em formato de síntese de elementos significantes, compreende o que se produz com a mixagem resultante do texto 1 e do texto 2 . Adverte-se que o texto 3 não é o mapeamento nem o mapeamento é uma narrativa. O elemento narrativo é o fundamento para atingirmos o objetivo de produzir um mapeamento do território de modo expressivo, buscando evidenciar outros aspectos e elementos que escapam ou se tornem invisíveis em mapas descritivos ou representacionais.

Antes de apresentar os resultados do procedimento e algumas análises no contexto da pesquisa em que ele se insere, abordaremos dois problemas suscitados no estudo coletivo do método e apontaremos algumas soluções.

\section{Objeções ao método}

A discussão com o grupo de pesquisa acerca do procedimento da mixagem de textos com a introdução da escrevivência trouxe duas objeções conceituais ao método: poderia um homem negro se apropriar da escrevivência, na medida em que ela surge como fruto da experiência de uma mulher negra? Essa objeção se sustenta nos estudos marxistas e feministas de Davis (2016) e suas comentadoras, que ressaltam o gênero como importante à análise sociocultural e econômica. Em segundo lugar, pareceu importante fundamentar o porquê de uma experiência vivida no âmbito pessoal poder assumir o status de algo que pode ser coletivo/ coletivizado e que escape ao narcisismo do privilégio de uma escolha teórica unilateral do pesquisador.

Para responder ao que me autoriza o ato de escreviver, sendo um homem negro, foi necessário voltar o olhar para um feito do feminismo negro. Sojourner Truth, mulher negra e abolicionista estadunidense, discursou improvisadamente na Convenção dos Direitos da Mulher, em 1851. Em E eu não sou uma mulher?, como ficou reconhecido o discurso, Truth mostra como a sociedade se comporta diante de uma branca e a uma negra, evidenciando, já no século XIX, o quanto há de problemático na universalização da categoria mulher sem a discussão de raça (Ribeiro, 2019). Necessário sempre lembrar que o branco constitui o elemento não marcado pejorativamente na sociedade e que representou há séculos a própria ideia de humanidade. Nas palavras de Isildinha Baptista Nogueira (2017), "a brancura é parâmetro de pureza artística, nobreza estética, majestade moral e sabedoria científica" (p. 124).

Ribeiro (2019) ressalta o problema da falta de visibilidade para discursos como os de Truth no decorrer dos séculos após a diáspora negra e propõe o conceito de lugar de fala, aparentemente como inflexão crítica e dialógica com os trabalhos sobre a fala dos subalternos (Spivak, 2010), e sobre quem pode falar do centro e da periferia do conhecimento (Hall, 2003). O ponto de vista feminista, que resulta no conceito de lugar de fala (Ribeiro, 2019), é defendido por Collins (1997) como produto de experiências históricas coletivas e compartilhadas que permitem ou não que certos grupos acessem lugares de cidadania, devido a marcadores sociais de raça, gênero e classe social. Com isso, Ribeiro (2019) reforça que o equívoco de pensar o lugar de fala como algo pessoal está em considerar a sociedade como um somatório de indivíduos em sua singularidade, esquecendo que certos indivíduos experienciam exclusões sociais, preconceitos e marginalizações da sua cultura e conhecimento como coletivos, a despeito de suas pretensas singularidades. É o caso dos negros e indígenas em nosso país. Como homem negro, tenho lugar de fala que me autoriza a operar com o tipo de narrativa a que me dedico nesta pesquisa: a do grapixo como prática de crítica e de denúncia, porém marginalizada e criminalizada.

Quanto à escrevivência, se a produção oral africana teve algum reconhecimento na construção cultural do Brasil, a produção escrita por muito tempo foi apagada e esquecida. Machado de Assis foi embranquecido para que suas obras não fossem atribuídas a um homem negro, e Maria Carolina de Jesus só é lembrada, quando muito, por Quarto de despejo. Partindo daí, entendemos a importância de confirmar, legitimar e exaltar a existência de autoras(res) negras(os), por constituir possibilidades novas de construções subjetivas para sujeitos negros ao recuperar o protagonismo em narrativas próprias. Eis uma característica de importância vital da escrevivência, além da questão de gênero objetada. Outra característica da escrevivência a ser respeitada está no fato de ser crítica a hegemonias de classe, raça e gênero, e de não recuar a denunciar a injustiça histórica cometida com o povo negro a partir da escravização. Almeida (2018) traz uma passagem de Conceição Evaristo na abertura da FestiPoa Literária de 2018 em que, ao ser perguntada sobre quem pode e quem não pode escreviver, responde o seguinte: "este conceito pode ser utilizado para pensar em um contradiscurso em relação ao hegemônico na literatura, tanto por mulheres negras, mas também por homens negros. Mas sempre atentando-se ao propósito de incomodar o estabelecido, incomodar os da Casa Grande" (p. 8).

Ao respeitar os princípios da escrevivência, o grapixo e a poesia do rap podem contar histórias que fazem a crítica da Casa Grande e dizem de uma experiência coletiva. Penso que a autorização de Evaristo e minha assunção do lugar de fala como homem negro, cuja escrevivência seja crítica em relação ao hegemônico, respondem às objeções acerca da construção metodológica e da prática da mixagem de textos no processo de reconhecimento de territórios - espaço, relações e processo histórico baseado em narrativas. 


\section{Resultados da mixagem de textos como leitura/escuta de narrativas do território}

Nesta seção, apresentaremos quatro exemplos de mixagens e, em seguida, as primeiras análises que sustentam o método como adjuvante da produção de mapas expressivos a partir de narrativas do território. Passamos a reutilizar a primeira pessoa do plural por se tratar de uma análise conjunta dos autores deste artigo, sustentados no trabalho do grupo de pesquisa.
Nos Quadros 1, 2, 3 e 4 se encontra cada procedimento da mixagem da seguinte forma: o texto 1 (grapixo), o texto 2 (poesia) e o texto 3 (síntese de elementos para o mapeamento, resultante da mixagem do texto 1 e do texto 2). Concluiremos o artigo apresentando algumas análises acerca dos resultados para verificar a pertinência e a validade do procedimento segundo os objetivos da pesquisa, a saber, a construção de um modo de ler/escutar e produzir um mapeamento expressivo do território baseado em narrativas.

\section{Mixagem 1}

Quadro 1. Primeira mixagem

Texto 1 (grapixo): "Passam os anos... e a rotina é a mesma"

Texto 2 (poesia): LUTO (Jango)

Oh mãe, eu tô cansado

E eu tô cansado de ficar cansado

Ultimamente eu tenho pensando em tudo que nós tem passado

Tipo, a gente correndo pra caralho pra conseguir pagar as contas e, ainda assim, no final do mês, ser humilhado

Mentiram pra gente quando disseram que deus é brasileiro e anda do nosso lado

Aqui é nós por nós

Chorando... só a minha gente

Sorrindo... o algoz

Mas é isso, né? Chora agora, ri depois

Ontem na garganta eu tinha voz

Hoje eu escrevo poesia

Amanhã, se eu conseguir, eu solto a voz

Mas oh mãe, eu tô cansado

E eu tô cansado de ficar cansado

Se a gente fosse rico, seria muito mais fácil

Queria ter herdado as glórias, os ouros

As joias, os tesouros daquele passado

Daquele passado que eu tive que aprender sozinho

Porque no colégio não me ensinaram

Não me contaram que meus antepassados eram reis e rainhas

Só que eles foram escravizados

Se eu soubesse disso na infância teria sido outro papo

Nunca gostei de ser chamado de agressivo, revoltado

Também nunca gostei de ser chamado de João Pedro,

mas era assim que me chamavam

Meu sangue tá escorrendo

Nessas calçadas ele tá sendo espalhado

E ele é precioso, tipo O-

Vai saber quanto tempo vai demorar pra ser estancado

Com 14 anos, João Pedro foi assassinado

Quando ele se foi, eu também morri um pouco

Daqui a pouco vem algum branco gritando João Pedro presente

É que vocês só se lembram da gente quando a gente tá morto

Tipo, João Pedro presente, João Miguel presente

Kauã Ribeiro presente, Kauan Peixoto presente

Marcos Vinícius presente, Ágatha Félix presente

Marielle presente...

Jango? Tá ausente

Ficou em casa, disse que tava mal

Não sei se eu tô bem

Não sei se eu tô mal

Um moleque de 14 anos morreu e eu não consegui chorar

Se bem que eu ainda não consegui chorar a morte do Baum

ipo Kamau, se me perguntarem se eu tô bem... tô bem

Procurando meu nirvana como Kurt Cobain

Ando mentindo tanto que tô quase acreditando nessas merdas Mas daqui a 23 minutos vai ter mais um jovem negro morto na mão desses pela 
Quadro 1. Continuação

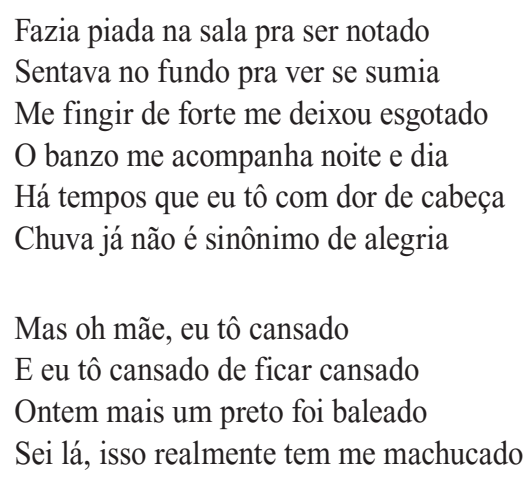

\author{
Essa eu escrevi em 20 minutos \\ Recitei em 2 minutos \\ Que é pra sobrar um minuto em forma de respeito \\ Um minuto de silêncio \\ Hoje eu tô de luto \\ Amanhã eu levanto mais cedo e luto \\ Hoje eu tô puto \\ Agora eu preciso de me recolher, porque é mais uma mãe preta de luto
}

Texto 3 (síntese de elementos narrativos do território): Um passado de exclusão e violência se atualiza cotidianamente. A visibilidade do corpo negro o aproxima da morte. Só pode ser presentificado se não houver mais corpo.

O grapixo Passam os anos... e a rotina é a mesma se mixou com uma poesia cujo ritmo é marcado por uma temporalidade implícita em particípios e gerúndios. Sequências de termos que remontam ao passado (baleado, machucado, estancado, espalhado, assassinado) referem-se diretamente a um presente reiterado (chorando; [sangue] escorrendo). O texto do muro apresenta a mesma estrutura na qual a passagem do tempo leva a um eterno retorno. Um tempo em movimento circular como o dos pratos de toca discos onde o DJ faz suas mixagens, caberia a metáfora.

O termo "presente" é nominalmente referido na mixagem no contexto da denúncia de que o corpo negro costuma ser lembrado apenas em sua ausência, depois de morto, como nos atos de nomear alguém que foi violentado, assassinado, afirmando sua presença entre nós, in memoriam. A invisibilidade é frequentemente imposta aos subalternizados da civilização. A filosofia e a história negra têm ocupado algum lugar fora da sombra apenas recentemente na academia. Contudo manifestações artísticas ou de protesto, como o grapixo, são criminalizadas. $\mathrm{O}$ corpo daquele que grapixa, se estiver presente na cena, será encarcerado. Seu ato público só se verifica em sua ausência.

Grada Kilomba (2019) sustenta sua tese de um passado que se reproduz cotidianamente na vida de um(a) negro(a). A recordação da plantation não é um trauma que envolve o sujeito negro/a em repetições neuróticas por ainda carecer de elaboração psíquica, como em Freud (1914/2010), mas a atualização implacável de um passado de escravização e racismo que se reproduz em cenas cotidianas de segregação e criminalização, entre outras violências.

O tempo entre duas mortes de um homem negro, situado na estatística dos 23 minutos (Marques, 2017) que ainda permite um minuto de silêncio além do tempo da escrita e da recitação da poesia, ressoa na mixagem com grandiloquência, revelando mais uma nuance de experiência coletiva implícita na narratividade do grapixo.

$\mathrm{O}$ retorno ao passado para significar o presente e reconstruir um futuro possível e menos trágico, como ensina Abdias Nascimento (2019), é um dos sentidos do ideograma dos povos acã da África Central chamado Sankofa, cuja representação mais popular é a de um pássaro que inclina seu pescoço para trás em busca de uma semente.

\section{Mixagem 2}

Quadro 2. Segunda mixagem

\begin{tabular}{|l|l|}
\hline Texto 1 (grapixo): “Em breve aqui um jardim” & \\
\hline Texto 2 (poesia): BANZO (Jango) & Eu tô cantando pra Oyá \\
Aqui eu não me sinto bem & $\begin{array}{l}\text { Pra ela afastar de mim todo o mal } \\
\text { Pra ela trazer as lembranças que eu tinha do Baum } \\
\text { Eu não me sinto em casa aquele passado de glórias se torne atual }\end{array}$ \\
Meu cansaço não passa & $\begin{array}{l}\text { Pra aqu } \\
\end{array}$
\end{tabular}

Continua... 
Quadro 2. Continuação

É que, tipo assim, é muita mágoa
Meu corpo tá transbordando
Nem o Atlântico carrega tanta lágrima

Eu tô buscando África

É que eu tô com saudade

Eu já não me sinto tão bem nessas ruas

Da mesma forma que eu não me sinto pertencente à faculdade

É que eu tô com saudade de olhar o mar

Pôr os pés nas águas da rainha de Aiocá

Sentir o abraço de Iemanjá

Eu sei quem segura as pontas pra mim são:

Minhas avós, minhas mães, meus orixás

Mas ainda sinto o peso do mundo nos meus ombros

Me disseram que o mundo é diferente da ponte pra cá Só que a ponte quebrou e o que restou foram escombros Me disseram que o mundo é diferente do oceano pra cá Só que esse mundo tá louco, tô me sentindo meio catatônico

Juro, tá osso

Minha geladeira regada a água e ovo

Até os menorzinhos que tão vivo já tão mortos

Eu já não carrego comigo aquele sorriso no meu

rosto, nem aquele brilho no meu olho
Eu tô dançando pra Odé

Pra que pra casa ele me mostre o caminho

Pra me conectar com a terra, deixar de ser tão mesquinho

Pra que até nos piores dias eu não me sinta tão sozinho

E eu sei que eu não tô sozinho

Eu tenho milhões de irmãos comigo no exílio

Mas até a oitava eu tava sozinho

E isso fodeu comigo

Eu tive que embranquecer até a parte mais íntima da minha alma

Eu não sei se escrever me acalma

Meu eu ponho muita coisa pra fora nessas canetadas

Eu já disse: eu quero voltar pra casa

Eles não me querem aqui

Eu não queria estar aqui

Um dia eu vou embora daqui

Vou junto do meu Ori

Quem sabe eu volte a sorrir

Isso é papo de buscar um sul

É sobre buscar uma ancestralidade

Entender que eu não sou só um

E que as minhas referências vão além do

que me mostram na faculdade

Entender que a minha palavra não é só minha

Que eu descendo de reis e rainhas

Entender que eu tenho banzo, não depressão

E que o que a minha mãe fez por mim não pode ser em vão

Texto 3 (síntese de elementos narrativos do território): Sensação de não pertencimento ao lugar. Saudade de um lugar que está na memória ancestral. Esperança de um tempo breve para a mudança.

A saudade da terra distante somada à incerteza de um possível retorno para sua casa e o que será feito dessa casa em sua ausência desencadeia uma nostalgia mortal que acometia os negros vindos de África. Essa é uma explicação do que é o Banzo e, também, da própria poesia. Marcos da Silva e Silva (2018) traz o sujeito negro, pensando na sua condição existencial, marcado por uma busca de apropriação satisfatória do lugar de si. O grapixo, Em breve aqui um jardim, não poderia tão bem se mixar com a poesia se não trouxesse uma memória ancestral junto dela, isto é, uma possibilidade de voltar para casa ou de enfeitar onde se mora (o jardim) para que esta terra hostil se torne um pouco mais agradável e que, assim, também se diminua o sentimento de não pertencimento. Silva (2018) defende que Banzo é ancestral na medida em que a representação real da condição existencial do Ser-Negro perdura.

Essa mixagem também revela outra faceta dessa memória ancestral. Nessa busca por um lar, buscam-se lembranças que trazem acalanto ou situações de conforto. Roger Cipó (2019) compartilha algumas dessas imagens que dizem respeito a um tempo passado, por exemplo, o som de um berimbau ou de um atabaque, que carrega alguns dos significados de Banzo, do quicongo mbanzu, que expressam saudade, paixão ou mágoa (Silva, 2018). 


\section{Mixagem 3}

Quadro 3. Terceira mixagem

Texto 1 (grapixo): "Cadê os porco?"

Texto 2: JANGO LIVRE (Jango)

Esses dias tomei um enquadro na quadra

O policial veio todo $p a$ com o dedo na minha cara

Dessa vez eu tive sorte

Podia ter sido uma quadrada

Ainda assim fiquei de cara com esse cara

Minha pele já foi banhada a ouro

Na luz da lua ela é tipo prata

Hoje a minha vida não vale nada

A dualidade da vida e morte pro preto é tipo cara ou coroa Se eu morrer, como é que fica a minha coroa?

Eu vim de África, sou realeza

Meu cabelo é minha coroa

E eu tô cheio de verdades pra falar

Doa a quem doer

Oh Febem, se nós se matar

Quem é que mata o Matuê?

Eu tô caminhando contra o vento

Sem dinheiro, sem lenço

Mas sempre com o documento

Eu não posso me esquecer que eu sou preto

O sonho deles é me fazer de detento

Exu me leva e me traz

Mas ainda sigo atento

E eu sigo com o corpo fechado e a cara amarrada

Minhas poesias são minhas Horcruxes

A cada linha eu ponho minha alma

Desses caras eu acho graça

Na internet tão pedindo pra apagar as paradas porque tá dando gatilho

No enquadro eu tô pedindo pra Oxalá não

deixar o policial puxar o gatilho

É papo dez, não minto

Não existe Jango Livre se tem preto que não é livre

E nisso nem tem trocadilho

Tamo nos vendendo por menos de um salário mínimo
Essa é a escravidão moderna

Preto sem trabalho é considerado vagabundo pela polícia Então seria a carteira de trabalho a nova carta de alforria? Sepá que não...

Vi minha mãe sair de casa pra trabalhar às 5 da matina Vi minha mãe voltar do trabalho só no outro dia Quando criança, via minha mãe só no domingo e cês querem me falar de ter empatia?

Presta atenção no que eu tô te falando

Esse ano eu saio do Serasa

E fico rico até o fim do próximo ano

E quando eu ficar rico, lá em casa não vai faltar:

Luz, bisnaguinha, nem iogurte

Vou tomar de assalto tudo o que é nosso, pique Robin Hood Eu tô cheio de planos, mas nenhum deles é de saúde

E quando eu ficar rico, lá em casa não vai faltar:

Luz, bisnaguinha, nem iogurte

Vou tomar de assalto tudo o que é nosso, pique Robin Hood Eu tô cheio de planos, mas nenhum deles é de saúde

Vou escrever uns versos

Tipo Jorge Aragão em Coisas de Pele

Tô tentando sair da merda

E vocês querendo me vender que merda faz bem pra pele

O mundo tá acontecendo lá fora e eu trancado no meu quarto O ano não é 1964

Esse Jango não é branco

Nem importante pra nação

E se morrer não vai ser lembrado

Mas Jango tá vivão

Tipo aquele filme

Jango se tornou livre por ser revoltado

E a minha morte não será em vão

Texto 3 (síntese de elementos narrativos do território): Afirmação da prisão do corpo negro e da criminalização de sua cultura. Racismo. 
O grapixo-escrevivência Cadê os porco? é mixado com uma poesia-escrevivência que remete à relação problemática do sujeito-especialmente o homem-negro com a polícia, como representante repressiva e violenta do Estado. Recentemente, um movimento mundial tomou as ruas para afirmar a importância das vidas negras, denunciando a necropolítica estatal, nos termos de Achille Mbembe (2018), em relação a quem tem o marcador fenotípico de pele escura, especialmente em países do Ocidente. O sentido apressado de um apelo pela presença da polícia na frase do muro se estilhaça na poesia que revela outras expressividades narrativas: a subcidadania reiterada de pessoas que precisam portar documentos de identificação sob pena de serem abordadas pela força policial que as coloca em suspeição; a liberdade negada e a revolta justificada contra um Estado violento e uma sociedade excludente.
A liberdade de Django, no filme Django livre (Sher, Hudlin, Savone, \&Tarantino, 2012), não é conquistada sem sangue derramado. Fanon (1979) critica o uso político do discurso de paz por aquele que, por sua vez, usou da violência para exercer seu poder de subjugação do outro. O colonialismo se sustentou no uso da força militar para ocupação do território, subjugação violenta e destruição da cultura de um povo que, posteriormente, será acusado de violência caso reaja em nome de sua liberdade. O misto de revolta e de apelo, antes implícitos, surgem da mixagem estabelecendo outras expressões na narrativa do território.

Cadê os porco?, escutado após o método da mixagem, proporciona o letramento acerca da experiência das condições e formas de vida na periferia das grandes cidades. Há um saber que se revela na noção de que Django nunca será livre enquanto outros pretos também não o forem.

\section{Mixagem 4}

Quadro 4. Quarta mixagem

Texto 1 (grapixo): "Te expus um livro de opções mais as suas decisões optaram pelo silêncio"

Texto 2: FALCÃO (Jango)

Aí garçom, desce mais uma que hoje eu

tenho muita coisa pra escrever

Eu já não tenho medo de morrer

Eu sei desde os 13 que eles não vão me tratar com carícias

É aí que nasceu minha malícia

Mas é que eu tenho que ter malícia

Pra não virar notícia

Eu tenho nojo dessa farda, mano

Foda-se a polícia

Eles não ligam pra nossa existência

Minha mãe falando que eu preciso ter resiliência

E só me vem aquela do Hércules Marques:

"Eu cansei de ser resistência, tô precisando é de um abraço"
Mas o tempo tem passado

Os amigos ficaram no passado

Minha raiva tem aumentado

Meu pai tá em outro estado

A gente não tem se falado

Sei lá, eu tô melhor assim

Eu sei quem corre por mim

Quem chora por mim

Quem morreu e quem morreria por mim

E no rádio aquela música não sai do repeat

"TRISTEZA NÃO TEM FIM, FELICIDADE SIM"

Mas, se tristeza não tem fim, a luta também não

O que a minha mãe fez por mim não pode ser em vão

Eu tô sonhando tão alto que me chamam de falcão

E eu era tipo: jovem, preto, novo, pequeno

"Jango, cuida de ti que na rua é só veneno"

E geral dizia que meu bairro era só: drogas, armas, sem futuro

Mas tem vários pretos tipo eu ganhando o mundo 
Eu virei uma mistura de ódio e cansaço

Fazia tempo que eu não chorava

Quando veio deixou meus olhos num puro inchaço

Mas me responde: quem é que nota a lágrima do palhaço?

Lembrei o que um mano meu me falou

"Um corpo negro não cai por um único motivo"

Eu tô vendo meus irmãos morrer desde os meus 6 anos

Não é à toa que meu olhar é caído

Eu tô abatido e abatido sigo

Os professores na faculdade me olhando como se me falassem

que há muito eu devia ter desistido

Mas eu tô tipo o meu pai há uns anos atrás, mano

Não ligo

Eu já perdi a conta de quantas vezes a felicidade bateu

na minha porta

E eu não abri com medo de ser o proprietário

Eu não quero mais ser despejado

Tenho mó saudade de uns amigos

Da época que a gente era aliado

De quando a gente era lado a lado
E eu queria ser que nem o BIG - notório

Mas, se me matarem, eu sei que não vão trocar nem o nome do diretório

E, se me matarem, não fiquem de luto, façam uma revolução ao invés de irem no meu velório

Sejam tipo aquele personagem que mata nazistas em Bastardos Inglórios

Tudo nessa vida é ilusório

Ainda tô procurando minha terra prometida, vou defender meu território

É um milagre eu não ter ido pro "reformatório"

Cês conseguem entender porque eu tenho tanto ódio?

As pintas tão se achando maçom

Fumando pontas, bebendo Red Label

Mas foda-se, eu sou campeão

Vou buscar meu fio de contas com meu amor

Eu tô sem tempo, irmão

Sei que tem muitos contra, mas tem alguns a favor

Aí garçom, pede lá pra fechar a conta, por favor

Texto 3 (síntese de elementos narrativos do território): Reafirmação da invisibilização, da saudade de um lugar próprio, do cansaço, da ancestralidade.

Por fim, o grapixo Te expus um livro de opções... foi escutado na mixagem com o poema "Falcão", produzindo uma verdadeira síntese em relação às mixagens precedentes. Perceba-se que nesta encontramos reafirmações da ancestralidade de matriz africana, da invisibilização subjetiva no espaço territorial, do cansaço que pode levar ao silenciamento completo. Silenciamento e invisibilidade, banzo, não pertencimento, cansaço da repetição inexorável de segregação e da violência. Vigilância do corpo, criminalização do ato. Racismo. A saturação das temáticas indicou que o corpus da pesquisa era, então, satisfatório para as análises e discussões com vistas à conclusão.

\section{Discussões finais e novas aberturas}

Um bom procedimento de pesquisa em nosso campo é aquele que produz novas perguntas, além de suas primeiras respostas. Parece claro que o método da mixagem de narrativas, seguindo seu rigor metodológico e fiel a sua epistemologia, mostrou capacidade de revelar outras camadas discursivas que constituem realidades menos visíveis daquele território. Porém cabem algumas perguntas: em que medida o encontro com as narrativas dos recantos e dos muros também não foram efeitos da deriva de um homem negro, estranho ao território, com quem as pessoas têm receio de conversar? Entretanto, em que medida só um homem negro, que sente na pele a memória cotidiana da plantation reiterada em nosso tempo (Kilomba, 2019), poderia dar ouvidos a certas narrativas subalternizadas (Spivak, 2010) no território e no laço social?

Há muitas letras nas paredes e nos muros das cidades. Quem sabe ler a letra sem apressadamente the atribuir sentidos narcísicos ou provenientes de um coletivo alienado em seu preconceito de classe, raça ou gênero (Davis, 2016)? O documentário A letra e o muro (Di Azir Cantor Professor Stanislaw Azir, 2002), dirigido por Lucas Frentin, mostra o valor e o propósito expressivo antissistema de escritas que, no senso comum, não são compreendidas como manifestações legítimas, mas consideradas ora vandalismo, ora analfabetismo, por pessoas brancas de classe média, moradoras de bairros mais centrais. A busca pela expressão em vez da representação ou da significação apressada sob o ponto de vista daquele que escuta uma narrativa tem por objetivo atenuar esse narcisismo que traduz em seus próprios termos a fala ou escrita do Outro, aqui entendido na sua radical diferença. $\mathrm{O}$ indivíduo de pele preta sempre foi 
falado e raramente escutado sobre sua perspectiva cultural, social e histórica, num processo de infantilização, como aponta psicanaliticamente Lélia Gonzales (1984).

Acolhemos a objeção de saber se apenas um sujeito que sofre com os mesmos marcadores sociais teria possibilidade de escutar narrativas silenciadas do território. Esse problema demandaria o fôlego de um novo artigo. Contudo o que foi possível aprender neste trabalho é que qualquer resultado de uma leitura/escuta ou mesmo de um levantamento de dados quantitativos pela via de alguma teoria ou técnica científica privilegiadas no estudo, as narrativas de um território que se deseja reconhecer voltariam a ser capturadas numa rede interpretativa prévia, resultando em algo da mesma estrutura de preconcepções provenientes de sensos compartilhados em um discurso hegemônico no laço social.

Portanto, na lógica da atenuação desses efeitos que norteia eticamente nosso processo de pesquisa, a psicanálise aparece no contexto desta pesquisa não como técnica interpretativa que define supostos sentidos inconscientes das narrativas, mas unicamente como inspiradora do ato da construção coletiva entre aquele que narra e aquele que escuta (Freud, 1937/1996). Daí a consideração da necessidade de problematizar e constituir uma transferência como condição da leitura/escuta de narrativas. Ainda assim, pode-se objetar que aquele que lê/escuta narrativas grapixadas no território corre o risco de produzir, com sua mixagem, uma construção igualmente narcísica, egóica, preconcebida. O risco é possível e por isso foi preciso analisar o resultado obtido neste trabalho com alguns conceitos elementares do método aqui descrito. Ressaltamos dois deles: (1) a justificação do caráter de escrevivência que homogeneíza o texto do território e o texto do pesquisador, e autoriza a mixagem entre ambos; (2) a confrontação do resultado das mixagens com a bibliografia de pensadores da epistemologia do pensamento negro de referência e atualidade acadêmicas, que comprovaram o caráter generalizável e coletivo dos achados.

$\mathrm{Na}$ escrevivência, é preciso que a escrita tenha o caráter de inquietar o poder estabelecido e falar da experiência de um coletivo. Assim podem ser tomadas as narrativas em forma de grapixo, o que impôs que os poemas aos quais os grapixos foram mixados para produção narrativa do território também o fossem. É o que parece ter sido garantido pela confrontação com os referenciais bibliográficos estudados. O passado de exclusão e violência que se atualiza cotidianamente (Kilomba, 2019; Mbembe, 2018), a negação da fala desde o centro (Hall, 2003; Spivak, 2010), as estatísticas que comprovam o terrorismo de Estado contra o sujeito negro, cujo corpo visível e presente na rua o aproxima da morte ou do encarceramento, são condições que indubitavelmente falam de experiências coletivas. Além delas, o banzo - assim como a esperança da chegada de um tempo de descanso em que o passado escravizador pare de retornar cotidianamente e a fé na espiritualidade de matriz africana - também não pode ser assumidos como resultado de uma escuta narcísica das narrativas encontradas no território da pesquisa.

No processo de colocar à prova o método da mixagem, encontramos outra maneira de tomar o grapixo como narrativa válida e central de um território urbano, mas não como algo inquestionável, nem confiável como se confia na autoridade de um griot. Para escapar de capturas interpretativas ou reificações, o trabalho no registro da expressão deu contornos a ideias, frases, imagens e ligações resgatadas de outro texto-experiência guardado numa memória que, ao final, parece ter produzido um terceiro texto narrativo que transcende e revela outras camadas discursivas que estavam presentes na fina camada de tinta sobre os muros do território.

Além da contribuição com o método de mapeamento a partir de narrativas do território da pesquisa na qual este trabalho se insere, esperamos continuar desenvolvendo esta nova maneira de ler/escutar para que se abra espaço a outras tantas narrativas que sempre estiveram presentes, mas que foram, literalmente, colocadas à margem ou em um plano menor. Como efeito potencial da pesquisa, também esperamos contribuir para que haja conscientização sobre a função narrativa do grapixo que excede em muito a excentricidade, o vandalismo e a incivilidade frequentemente atribuídos a quem o pratica.

\title{
Mixing as reading/listening to territory narratives
}

\begin{abstract}
This article is an excerpt from original research aiming at recognizing territories from their narratives. The territory clinic method, based on drifting, listening and writing, to map, was tried out by the main author under the co-author's advisement. Sentences and expressions written on walls, here called "grapixos," were read as territory narratives based on a construed process called "text mixing." This paper seeks to present the mixing proposal as a way to read/listen to narratives of territorial spaces and to analyze their problems, potentialities, and results. Its main result shows that mixing grapixos with the researcher's "escrevivência" an appropriate method to reveal discursive layers of the territory concealed or silenced.
\end{abstract}

Keywords: mixing, reading, listening, narrative, territory. 


\section{Le malaxage comme lecture/écoute des récits du territoire}

Résumé : Cet article résulte d'une recherche originale visant à reconnaître les territoires à partir de leurs récits. La méthode de la clinique territoriale, basée sur la dérive, l'écoute et l'écriture, pour cartographier, a été expérimentée par l'auteur principal sous la direction du co-auteur. Les phrases et les expressions écrites sur les murs, appelées ici « grapixos », ont été les comme des récits du territoire basés sur un processus construit appelé « malaxage de textes». Cet article vise à présenter la proposition du malaxage comme un manière de lire/écouter les récits des espaces territoriaux et d'analyser leurs problèmes, potentialités et résultats. Son principal résultat montre que le malaxage des grapixos avec «l'escrevivência » du chercheur est une méthode pertinente pour révéler les couches discursives du territoire cachées ou silencieuse.

Mots-clés : malaxage, lire, écouter, récit, territoire.

\section{La mezcla como lectura/escucha de narrativas del territorio}

Resumen: El artículo resulta de una investigación autoral que pretende reconocer los territorios desde sus narrativas. El método de la clínica del territorio, basado en la deriva, la escucha y la escritura, para cartografiar, fue ensayado por el autor principal bajo la guía del coautor. Las frases y expresiones escritas en los muros, aquí llamadas "grapixos", se leían como narrativas del territorio a partir de un procedimiento llamado "mezcla de textos". El artículo busca presentar la propuesta de mezcla como una forma de leer/escuchar las narrativas de los espacios territoriales y analizar sus problemas, potencialidades y resultados. Su resultado principal muestra que la mezcla de grapixos con las "escrevivências" del investigador es un método pertinente para revelar capas discursivas del territorio ocultas o silenciadas.

Palabras clave: mezcla, lectura, escucha, narrativa, territorio.

\section{Referências}

Almeida, A. G. D. (2018). A história de A.: escrevivências de um aluno cotista negro no curso de psicologia da UFRGS. Porto Alegre, RS: Universidade Federal do Rio Grande do Sul. Recuperado de https://bit.ly/3r7Be58

Careri, F. (2003). El andar como práctica estética. Barcelona: Gustavo Gilli.

Cipó, R. [@rogercipo]. (2019, 17 dezembro). A sempre urgente necessidade de falar sobre subjetividades, memória ancestral, epigenética, escravização, colonialismo na luta anti-racista [Foto]. Instagram. Recuperado de https://bit.ly/39KZcZe

Collins, P. H. (1997). Comentário sobre o artigo de Hekman "Truth and Method: Feminist Standpoint Theory Revisited": onde está o poder? Signs, 22(2), 375-381.

Davis, A. (2016). Mulheres, raçae classe(H. R. Candiani, Trad.) - - São Paulo, SP: Boitempo.

Debord, G. (2003). Teoria da deriva. In P. B. Jacques (Org.), Apologia da deriva: escritos situacionistas sobre a cidade/Internacional Situacionista (pp. 87-91). Rio de Janeiro, RJ: Casa da Palavra.

Di Azir Cantor - Professor Stanislaw Azir. (2002). A letra e o muro-documentário sobre pichação (pichação) [Vídeo]. YouTube. Recuperado de https://bit.ly/3CRLTU2 -

Dunker, C. L. I. (2017). O que significa método em psicanálise? In C. E. Lang, J. S. Bernardes, M. A. T. Ribeiro,
S. V.Zanotti(Org.), Clínicas: pesquisas emsaúde, psicanálise e práticas psicológicas (pp. 13-32). Maceió, AL: Edufal.

Evaristo, C. (2017). Becos da memória. Rio de Janeiro, RJ: Pallas. Fanon, F. (1979). Os condenados da terra (J. L. Melo, Trad., 2a ed.). Rio de Janeiro, RJ: Civilização Brasileira.

Freud, S. (1996). Construções em análise. In Edição standard brasileira das obras psicológicas completas de Sigmund Freud (J. Salomão, Trad., Vol. 23, pp. 271-287). Rio de Janeiro, RJ: Imago. (Trabalho original publicado em 1937)

Freud, S. (2006). A dinâmica da transferência. In Edição standard brasileira das obras psicológicas completas de Sigmund Freud (J. Salomão, Trad., Vol. 12, pp. 107-120). Rio de Janeiro, RJ: Imago. (Trabalho original publicado em 1912)

Freud, S. (2010). Recordar, repetir e elaborar: novas recomendações sobre a técnica da psicanálise II. In Obras completas: Observações psicanalíticas sobre um caso de paranoia relatado em autobiografia ("O caso Schreber"), Artigos sobre técnica e outros textos (P. C. Souza, Trad., Vol. 10, pp. 193-209). São Paulo, SP: Companhia das Letras. (Trabalho original publicado em 1914)

Gonzales, L. (1984). Racismo e sexismo na cultura brasileira. Revista Ciências Sociais Hoje, 223-244. Recuperado de https://bit.ly/3o4LdXg 
Hall, S. (2003). Da diáspora: identidades e mediações culturais. Belo Horizonte, MG: Editora da UFMG.

Kilomba, G. (2019). Memórias da plantação: Episódios de racismo cotidiano. Rio de Janeiro, RJ: Cobogó.

Marques, M. (2017). 'A cada 23 minutos, morre um jovem negro no Brasil', diz ONU ao lançar campanha contra a violência. Portal Geledés. Recuperado de https://bit.ly/31brj3V

Mbembe, A. (2018). Necropolítica (3a ed.). São Paulo, SP: N-1 Edições.

Nascimento, A. (2019). O quilombismo: documentos de uma militância pan-africanista. (3a ed.). São Paulo, SP: Perspectiva.

Nogueira, I. B. (2017). Cor e inconsciente. In $O$ racismo e o negro no Brasil: questões para a psicanálise (pp. 121-126). São Paulo, SP: Perspectiva.

Pereira, P. D. A. (2015). Griot-educador: a pedagogia ancestral negro-africana e as infâncias, em um espaço cultural afrogaúcha [Dissertação de mestrado]. Universidade Federal do Rio Grande do Sul, Porto Alegre, RS.

Pollak, M. (1992). Identidade e memória social. Estudos Históricos, 5(10), 200-212.

Prandi, R. (2001). Mitologia dos orixás. São Paulo, SP: Companhia das Letras.
Rap da Hora. (2020). Djonga - Histórias da minha área (Full Album) [Vídeo]. YouTube. Recuperado de https://bit.ly/315DJB5.

Ribeiro, D. (2019). Lugar de fala. São Paulo, SP Pólen.

Salles, E. (2007). Poesia revoltada. São Paulo. SP: Aeroplano. Sher, S., Hudlin, R., Savone, P. (Produtores), \& Tarantino, Q. (Diretor). (2013). Django livre [Netflix]. Estados Unidos: A Band Apart.

Silva, M. S. (2018). O banzo, um conceito existencial: um afroperspectivismo filosófico do existir-negro. Griot: Revista de Filosofia, 17(1), 48-60.

Spivak, G. (2010). Pode o subalterno falar? Belo Horizonte: Ed. UFMG.

Thiago Elniño. (2017). Thiago Elniño - A rotina do pombo (Álbum completo) [Vídeo]. YouTube. Recuperado de https://bit.ly/3nRSFVx.

Warburg Banco Comparativo de Imagens. (2021). Basquiat, Jean-Michel. Campinas, SP: Centro de História da Arte e Arqueologia. Recuperado de https://bit.ly/3DU3SKO

Recebido: $11 / 08 / 2020$

Revisado: 24/08/2021

Aprovado: 24/10/2021 